\title{
Correction to: Dynamics of lying
}

\section{Hans van Ditmarsch ${ }^{1}$}

Published online: 25 July 2018

() Springer Nature B.V. 2018

\section{Correction to: Synthese (2014) 191:745-777 \\ https://doi.org/10.1007/s11229-013-0275-3}

The original publication of the article is missing the funding information: Hans van Ditmarsch acknowledges support from ERC project EPS 313360.

$凶$ Hans van Ditmarsch

hans.van-ditmarsch@loria.fr

1 LORIA - CNRS, Université de Lorraine, Nancy, France 